\title{
REAVI
}

\section{ÉTICA PROFISSIONAL DOS ESTUDANTES DE CIÊNCIAS CONTÁBEIS: ANÁLISE DOS FATORES LIGADOS AOS VALORES INDIVIDUAIS}

\author{
Amanda Manes Koch ${ }^{1}$, Luísa Karam de Mattos $^{2}$, Leonardo Flach ${ }^{3}$ \\ Universidade Federal de Santa Catarina (UFSC) $)^{1,2,3}$ \\ amandamaneskoch@hotmail.com ${ }^{1}$, luisakmattos@gmail.com², leonardo.flach@gmail. $\mathrm{com}^{3}$
}

\begin{abstract}
Resumo
Posturas orientadas por valores éticos são valorizadas pela sociedade e pelo mercado de trabalho, porém não são seguidas de forma absoluta. Diante da frequência com que se noticiam fraudes envolvendo condutas antiéticas de profissionais contábeis, esta pesquisa contribui com o aprofundamento desta discussão sobre ética e abarca a fase inicial da carreira, da formação profissional, avançando na caracterização do perfil ético dos profissionais contábeis e intensificando a consciência ética nos estudantes e profissionais contábeis. O presente estudo tem o objetivo de analisar a percepção de estudantes de Ciências Contábeis sobre a ética profissional, considerando determinadas variáveis intervenientes ligadas a fatores individuais. O método de pesquisa utilizado classifica-se como quantitativo, descritivo e survey, com aplicação de questionário fechado. A amostra representa 214 estudantes da Universidade Federal de Santa Catarina. Os dados foram analisados com auxílio dos testes não paramétricos de Spearman e Kruskal-Wallis, post-hoc Dunn-Bonferroni. Os resultados indicam que os fatores individuais influenciam significativamente no ponto de vista dos estudantes acerca da ética profissional e que a disciplina Ética e Filosofia Política no curso de Ciências Contábeis tende a conscientizar os estudantes à cerca das responsabilidades e das condutas que devem ser seguidas pelos profissionais contábeis. Portanto, os fatores individuais somados à educação ética induzem de forma relevante as atitudes éticas dos estudantes. Contudo, essa afirmação trata apenas da amostra de análise deste estudo, uma vez que se encontram divergências ao comparar os resultados obtidos com os da literatura estudada.
\end{abstract}

Palavras Chave: Ética profissional. Contabilidade. Survey.

\section{PROFESSIONAL ETHICS OF ACCOUNTING SCIENCE STUDENTS: ANALYSIS OF INDIVIDUAL VALUES}

\begin{abstract}
Postures oriented by ethical and moral values are valued by society and by the labor market, but they are not followed absolutely. Given the frequency with which fraud involving unethical conduct of accounting professionals is reported, this research contributes to the deepening of this discussion about ethics, and encompasses the initial phase of career, professional education, advancing in the characterization of the ethical profile of accounting professionals and intensifying the ethical awareness in students and accounting professionals. The present study has the objective of analyzing the students' perception of the professional ethics, considering certain intervening variables related to individual factors. The research method used is classified as quantitative, descriptive and survey, with the application of a closed questionnaire. The sample represents 214 students from the Federal University of Santa Catarina. The data were analyzed Revista Eletrônica do Alto Vale do Itajaí - REAVI, v.08, n 13, p. 013-029, dez 2019 ISSN: 2316-
\end{abstract} 4190, DOI 10.5965/2316419008112019013 


\section{REAVI}

with the aid of the nonparametric tests of Spearman and Kruskal-Wallis, post-hoc DunnBonferroni. The results indicate that the individual factors influence significantly in the students' point of view about the professional ethics and that the discipline Ethics and Political Philosophy in the course of Accounting tends to make the students aware of the responsibilities and behaviors that must be followed by the accounting professionals. Therefore, the individual factors added to ethical education induce in a relevant way the ethical attitudes of the students. However, this statement deals only with the sample analysis of this study, because differences were found when comparing this study with the results of the literature.

Keywords: Professional ethics. Accounting. Survey.

\section{Introdução}

A ética é importante em todas as relações entre os indivíduos da sociedade, assim como no convívio profissional. Espera-se, desta forma, que comportamentos éticos sejam adotados no exercício profissional e que haja comprometimento e relação de confiança mútua entre os profissionais e seus clientes. Infelizmente, estas condutas não são seguidas de forma absoluta. A mídia frequentemente noticia fraudes, condutas antiéticas e casos de corrupção, que envolvem muitas vezes a classe contábil. Diante disso, percebe-se a relevância de abordar o tema ética com profissionais e estudantes de contabilidade.

Há um alto grau de responsabilização e compromisso no exercício da profissão contábil, por fornecer dados e informações relevantes aos seus usuários, auxiliando-os nas tomadas de decisões econômicas, financeiras e gerenciais. Além disso, dilemas éticos são enfrentados cotidianamente por esses profissionais, principalmente quando são atraídos a utilizar práticas indevidas no exercício de sua profissão (DELLA et al., 2014). Percebe-se, desta forma, a importância da educação ética nas universidades, uma vez que contribui na humanização dos estudantes e gera um senso de compromisso moral com a coletividade (ANZEH; ABED, 2015). Essa educação tem sido indicada como alternativa para promover a consciência ética e a tomada de decisão (JACKLING et al., 2007).

Lopes et al. (2006) destacam que as questões relativas à ética podem ser discutidas na academia pelos estudantes, porém eles trazem consigo fatores individuais que os acompanham desde a infância e que influenciam em suas condutas (LISBOA, 2010), como gênero, idade, religião e etnia. Segundo Feil (2016), o fato do comportamento humano ser diferente de indivíduo para indivíduo torna complexa a tomada de decisão de acordo com a conduta ética. Neste contexto, considerando variáveis independentes e o fato de que os estudantes de contabilidade possuem uma disciplina que aborda ética na graduação e geralmente estagiam ou trabalham na área, surge a pergunta de pesquisa: qual a influência das variáveis independentes na percepção ética dos estudantes de Ciências Contábeis? O objetivo do presente estudo é verificar a influência de fatores individuais como gênero, idade, experiência profissional, religiosidade, etnia e nível educacional na percepção ética dos estudantes de contabilidade, observando a relação entre as variáveis e o conhecimento dos estudantes.

Do ponto de vista prático, esta pesquisa contribui por fomentar a discussão sobre um tópico central na atividade profissional do contador: o comportamento ético. Diversos noticiários já reportaram escândalos de fraudes envolvendo a parte contábil de empresas, como as notícias internacionais da empresa Enron, e as notícias nacionais envolvendo as empresas que foram multadas pela Operação Lava Jato. Diante disto, este estudo contribui para o aprofundamento desta

Revista Eletrônica do Alto Vale do Itajaí - REAVI, v.08, n 13, p. 013-029, dez 2019 ISSN: 23164190, DOI 10.5965/2316419008112019013 


\section{REAVI}

discussão sobre ética na fase inicial da carreira, pela percepção do estudante, que está em formação profissional. Além disso, o estudo avança na caracterização do perfil ético dos profissionais contábeis e intensifica a consciência ética nos estudantes e profissionais contábeis.

Do ponto de vista teórico, pesquisas atuais sobre ética têm sido aplicados com profissionais contábeis (WEILER, 2017; FEIL; DIEHL; SCHUCK, 2017), em virtude dos dilemas éticos da profissão, da pressão pela maximização dos lucros e dos resultados, do espírito capitalista que passa a gerar dilemas entre os valores pessoais e profissionais. Shinzaki, Corrêa e Ferreira (2005) destacam que diante de comportamentos antiéticos que ocorreram e que foram noticiados, e também da eterna busca dos indivíduos pela maximização dos lucros por parte das empresas, o estudo sobre as questões e dilemas éticos da profissão contábil torna-se relevante. Cardoso, Souza e Almeida (2006) clamam por pesquisas com o objetivo de avançar na caracterização do perfil ético dos profissionais contábeis. Ademais, a contribuição deste estudo associa-se ao avanço do conhecimento empírico sobre o tema, ao intensificar a consciência ética dos estudantes e dos profissionais contábeis. Assim, segundo Feil, Diehl e Schuck (2017), os órgãos de classe podem formalizar eventos equiparados, de maneira a preparar os profissionais para exercerem suas funções com integridade e transparência, aumentando a credibilidade da informação contábil e contribuindo com a sociedade. Em relação aos estudos anteriores sobre ética, este estudo avança por analisar valores individuais da ética profissional, e em uma profissão que possui muita pressão em torno de valores financeiros e lucratividade, demandados pela empresa.

\section{Revisão teórica}

\subsection{A Ética e a Contabilidade}

A ética é o estudo da conduta com diretrizes em princípios morais, valores e obrigações, contendo escolhas reflexivas e padrões que envolvem o certo e o errado (OTALOR; EIYA, 2013). A ética está diretamente ligada à moral, sendo que a ética aponta o que pode ser considerado certo ou errado e a moral determina os princípios e regras de comportamento (VÁSQUEZ, 1997). Otalor e Eiya (2013) definem a ética como um conjunto de deveres morais e obrigações que indicam como os indivíduos devem se comportar na sociedade. Esses valores reconhecem o valor profissional como uma imagem de qualidade (MOTTA, 1984). O comportamento ético na perspectiva profissional também envolve fazer escolhas com base nas consequências de ações alternativas, podendo ser usado para explicar e compreender a conduta esperada pelos contadores (ONYEBUCHI, 2011).

A conduta ética é essencial na conservação da profissão contábil (MORAES; SILVA; CARVALHO, 2010). Sua prática traz como resultado o reconhecimento, a credibilidade, o respeito e a confiança, de forma a contribuir para o crescimento, a valorização e a continuidade dessa profissão (SANTOS; JESUS, 2002). Conforme Iudícibus et al. (2010), Marion (2012) e Otalor e Eiya (2013), o objetivo da contabilidade relaciona-se à geração de informações aos stakeholders, auxiliando-os na tomada de decisão. Sob esta lógica, torna-se essencial que os contadores tenham um compromisso ético, contribuindo para os negócios empresarias e para o bem-estar da sociedade em geral (CRISTINA; FLORINA, 2008). Segundo Parker (1994) e Smith (2003), a ética profissional incentiva os profissionais contábeis a observarem o código de conduta, reforçando a confiança da prestação de serviços.

Moraes, Silva e Carvalho (2010) destacam que a transparência e a fidedignidade das demonstrações financeiras tiveram um crescimento acelerado por todo o mundo. Porém, a mídia Revista Eletrônica do Alto Vale do Itajaí - REAVI, v.08, n 13, p. 013-029, dez 2019 ISSN: 23164190, DOI 10.5965/2316419008112019013 


\section{REAVI}

recentemente tem descrito os demonstrativos contábeis como falsos e fraudulentos (BAYOU; REINSTEIN; WILLIAMS, 2011). As condutas não-éticas levam à perda de confiança e da reputação dos profissionais contábeis (OTALOR; EIYA, 2013). Desse modo, não há a possibilidade em separar a contabilidade da ética, para que haja um equilíbrio na profissão e na sociedade (ARRUDA, 2003).

A conduta do profissional contábil é regida principalmente pelo Código de Ética do Profissional Contábil (CEPC), instituído pelo Conselho Federal de Contabilidade (CFC), que expõe expectativas de comportamento e punições para os infratores quando no exercício profissional e nos assuntos relacionados à profissão e à classe (ANJOS et al., 2011). Desta maneira, o CEPC contribui para aumentar a qualidade dos serviços prestados e a segurança do profissional e dos clientes na defesa da dignidade (CRISTINA; FLORINA, 2008). Conforme a Resolução CFC n. 803/96 (1996), alguns dos deveres contidos no código são: exercer a profissão com zelo, diligência, honestidade e capacidade técnica; guardar sigilo sobre o que souber em razão do exercício profissional lícito; inteirar-se de todas as circunstâncias antes de emitir opinião e auxiliar a fiscalização do exercício profissional.

\subsection{Estudos relacionados}

Em seu estudo, Feil, Diehl e Schuck (2017) analisaram as variáveis independentes de sua amostra e sua influência na conduta ética de estudantes de contabilidade. Por meio dos testes de Spearman, Kruskal-Wallis e post-hoc Dunn-Bonferroni, observaram que a consistência da educação ética aparece nas correlações significativas e que todas as hipóteses testadas relacionadas a gênero, idade, religiosidade, experiência profissional, número de disciplinas cursadas, etnia e se o aluno cursou ou está cursando a disciplina de ética, apresentaram diferenças significativas entre as médias. Identificou-se que os acadêmicos com maior atitude ética se relacionam ao gênero feminino, com mais de 20 anos, não praticantes de religião, atuam na área financeira, têm maturidade acadêmica e já cursaram ou estavam cursando a disciplina em foco (FEIL; DIEHL; SCHUCK, 2017).

Feil (2016) analisou as variáveis intervenientes na tomada de decisão ética do profissional contábil, identificando que os fatores individuais dos respondentes interferem no cumprimento do Código de Ética do Profissional Contábil (CEPC) e na tomada de decisão ética. Com base em sua amostra, verifica-se que 59\% dos profissionais contábeis concordam plenamente com a importância do código de ética como guia e 63,9\% concordam em cumprir tal código. Utilizou-se a correlação de Spearman, revelando que os contadores que seguem uma religião percebem o CEPC como um relevante guia de conduta (FEIL, 2016).

O estudo de Weiler (2017) buscou analisar a compreensão dos contadores em relação à ética profissional e a influência dos fatores individuais na resposta de cada entrevistado. Observase que os profissionais contábeis concordam quanto a importância do CEPC e sua influência na tomada de decisão. Além disso, verifica-se que os fatores religião, idade e experiência profissional são determinantes e influenciam na conduta do profissional. Em seus achados, aponta-se que quanto maior a idade do profissional contábil, maior é a tendência de consultar o CEPC durante o exercício da profissão (WEILER, 2017).

Em conformidade com Kish-Gephart, Harrison e Treviño (2010), as principais variáveis intervenientes que influenciam a decisão ética são características próprias de cada indivíduo, características de questão moral e características do ambiente organizacional. $\mathrm{O}$ foco do presente

Revista Eletrônica do Alto Vale do Itajaí - REAVI, v.08, n 13, p. 013-029, dez 2019 ISSN: 23164190, DOI 10.5965/2316419008112019013 


\section{REAVI}

estudo, assim como dos estudos relacionados, refere-se às características individuais: sexo, idade, religião, nível educacional e experiência profissional.

\section{Método de Pesquisa}

Quanto aos objetivos e à forma de abordagem, o estudo caracteriza-se como descritivo e quantitativo, respectivamente. Para coleta de dados utilizou-se o método survey, com aplicação de questionários fechados aos alunos de Ciências Contábeis da Universidade Federal de Santa Catarina (UFSC). A população de graduandos matriculados, no período a que se refere o estudo, corresponde a 815 estudantes de contabilidade. A amostra do estudo, porém, abrange 214 graduandos. Dentre esses, 180 referem-se a estudantes do período diurno e 34 do período noturno. O questionário foi enviado para a totalidade de estudantes de ambos os períodos, porém, os resultados representam cerca de $30 \%$ do total de estudantes matriculados. Apesar dessa restrição, considera-se que a amostra é relevante para o estudo.

O questionário foi adaptado dos estudos de Feil, Diehl e Schuck (2017) e foi composto por duas seções: perfil socioeconômico dos estudantes e conhecimento dos mesmos sobre a ética profissional. As informações foram tabuladas no programa Microsoft Excel, sendo que os respondentes foram dispostos nas linhas e suas respectivas respostas nas colunas. Os dados coletados foram codificados através da Escala Likert, como apresentado na Tabela 1. Não houve identificação dos estudantes e nem influência sobre as respostas.

As perguntas referentes ao perfil socioprofissional dos respondentes englobaram as variáveis sexo (V1), idade (V2), etnia (V3), se trabalham ou estagiam na área contábil (V4), se praticam algum tipo de religião (V5) e se já cursaram ou estão cursando a disciplina de Ética e Filosofia Política (V6), que faz parte da grade curricular obrigatória do curso de Ciências Contábeis da UFSC. Em relação à variável etnia, o participante, ao assinalar a opção "Outras", poderia descrever a etnia a qual pertencia. Dos entrevistados, cinco e seis disseram ser indígenas e espanhóis, respectivamente. As alternativas podem ser visualizadas na Tabela 1.

Tabela 1 - Questões que compuseram o questionário desta pesquisa

\begin{tabular}{c|c|c|c|c|c|c}
\hline \multirow{2}{*}{ Questões 1 a 8* } & Alternativas & $\begin{array}{c}\text { Concordo } \\
\text { totalmente }\end{array}$ & $\begin{array}{c}\text { Concordo } \\
\text { parcialmente }\end{array}$ & Indiferente & $\begin{array}{c}\text { Discordo } \\
\text { parcialmente }\end{array}$ & $\begin{array}{c}\text { Discordo } \\
\text { totalmente }\end{array}$ \\
\cline { 2 - 7 } & Escala Likert & 1 & 2 & 3 & 4 & 5 \\
\hline \multirow{2}{*}{ Sexo } & Alternativas & Feminino & Masculino & & & \\
\cline { 2 - 7 } & Escala Likert & 0 & 1 & & & \\
\hline \multirow{2}{*}{ Idade } & Alternativas & $0-20$ & $21-25$ & $26-30$ & $31-35$ & $>35$ \\
\cline { 2 - 7 } & Escala Likert & 1 & 2 & 3 & 4 & 5 \\
\hline \multirow{2}{*}{ Etnia } & Alternativas & Portuguesa & Alemã & Italiana & Outras* & \\
\cline { 2 - 7 } & Escala Likert & 1 & 2 & 3 & 4 & \\
\hline
\end{tabular}

Continua...

Revista Eletrônica do Alto Vale do Itajaí - REAVI, v.08, nº 13, p. 013-029, dez 2019 ISSN: 23164190, DOI 10.5965/2316419008112019013 


\section{REAVI}

...continuação.

\begin{tabular}{c|c|c|c|c|c|c}
\hline \multirow{2}{*}{$\begin{array}{c}\text { Pratica alguma } \\
\text { religião? }\end{array}$} & Alternativas & Sim & Não & & & \\
\cline { 2 - 7 } & Escala Likert & 0 & 1 & & & \\
\hline $\begin{array}{c}\text { Trabalha/estagia } \\
\text { na área contábil? }\end{array}$ & Alternativas & Sim & Não & & & \\
\hline & Escala Likert & 0 & 1 & & & \\
\hline $\begin{array}{c}\text { Cursa/cursando a } \\
\text { disciplina Ética e }\end{array}$ & Alternativas & Sim & Não & & & \\
\cline { 2 - 7 } Filosofia Política? & Escala Likert & 0 & 1 & & & \\
\hline
\end{tabular}

Fonte: Elaboração própria.

As Questões de 1 a 8 (Q1 a Q8) procuraram analisar o conhecimento dos estudantes de contabilidade sobre a ética profissional. Utilizou-se a Escala Likert nível 5, onde os respondentes tiveram a opção de concordar totalmente, parcialmente, não concordar nem discordar (indiferente), discordar totalmente ou parcialmente das afirmações do questionário. Cada participante deveria assinalar a alternativa que mais condissesse com a sua opinião.

As afirmações que compuseram o questionário para analisar o conhecimento ético dos estudantes foram: Q1: A disciplina Ética e Filosofia Política contribui na formação do profissional contábil; Q2: O Código de Ética do Profissional Contábil é importante na conduta profissional ética; Q3: O conteúdo do Código de Ética Profissional do Profissional Contábil apresenta informações suficientes, claras e precisas, quanto à conduta ética desse profissional; Q4: $\mathrm{O}$ contador tem a obrigação de guardar sigilo de todas as informações relacionadas às atividades operacionais de uma empresa; Q5: Sabendo-se que um colega de profissão está tendo atitudes antiéticas, o certo seria apenas alertá-lo sobre as consequências dos seus atos; Q6: O empregador poderia solicitar ao contador que cometesse atos contrários à legislação, e, caso não realizasse, poderia ser demitido; Q7: Os profissionais que cometem infrações visando vantagens próprias ou para terceiros, devem sofrer punições pelo CRCSC/CFC (Conselho Regional de Contabilidade de Santa Catarina/Conselho Federal de Contabilidade); e por fim, Q8: Imagine que você seja o contador e o dono de um escritório de contabilidade. Suponha que um de seus clientes tenha apresentado um lucro de $\mathrm{R} \$ 200.000,00$ ao final do ano de 2016 , e que ele peça sua ajuda para sonegar o imposto de renda declarando um lucro de $\mathrm{R} \$ 100.000,00$. O cliente alega que o dinheiro não pago em imposto será usado para movimentar a economia e gerar mais empregos. Ele acredita que há muita corrupção no governo e que a arrecadação do imposto de renda não será bem investido. Neste contexto, sua atitude como contador seria não sonegar imposto, apesar da justificativa do cliente.

Posteriormente, as informações foram submetidas às técnicas estatísticas não paramétricas. Para descrever e resumir os dados, utilizou-se a estatística descritiva. As correlações existentes entre as variáveis socioprofissionais e o conhecimento dos estudantes sobre a ética profissional foram analisadas através da correlação de Spearman, em função das características dos dados serem não paramétricos e nominais. As atitudes éticas dos estudantes foram analisadas em função das hipóteses referentes ao gênero, à idade, à etnia, à religião dos estudantes, à experiência Revista Eletrônica do Alto Vale do Itajaí - REAVI, v.08, n 13, p. 013-029, dez 2019 ISSN: 23164190, DOI 10.5965/2316419008112019013 


\section{REAVI}

profissional e à disciplina Ética e Filosofia Política. As hipóteses desta pesquisa são as seguintes: Hipótese 1 - A atitude ética é impactada positivamente pelo aumento da idade. Hipótese 2 - A atitude ética é impactada positivamente pela crença religiosa. Hipótese 3 - A atitude ética é impactada positivamente pelo aumento da experiência profissional. Cada uma destas hipóteses foi testada a um nível de confiança de $95 \%$ e uma margem de erro de 5\%. O teste Kruskal-Wallis foi aplicado para validação dessas hipóteses.

\section{Análise dos resultados}

\subsection{Descrição do Perfil Socioprofissional}

De acordo com a Figura 1, verifica-se que a maioria dos estudantes de Ciências Contábeis da UFSC do período diurno são do sexo feminino, abrangendo 56,11\% do total. Essa tendência é similar a apresentada no estudo de Weiler (2017), com 59\%. Já, o estudo de Feil (2016), revela que a maioria dos estudantes são do sexo masculino, e o estudo de Feil, Diehl e Schuck (2017), revela que $73,2 \%$ dos estudantes são do sexo feminino. Desta forma, pode-se concluir que as mulheres estão predominando na classe contábil ao passar do tempo. Este predomínio pode ser explicado pela inserção da mulher no mercado de trabalho, além dos projetos pela igualdade de gênero, incentivados pelo Conselho Federal de Contabilidade.

A idade até os 25 anos engloba 86,67\% dos estudantes, acima dos 72,7\% indicados na pesquisa de Feil, Diehl e Schuck (2017). Este índice pode ser explicado pelas políticas públicas educativas, que facilitam e incentivam o ingresso do estudante ao ensino superior.

Os estudantes, em sua maioria, possuem etnia portuguesa, seguida pela etnia alemã e italiana. Trinta e quatro entrevistados afirmaram possuir outra etnia, como japonesa, angolana e francesa.

Figura 1 - Perfil social dos estudantes (período diurno e noturno)

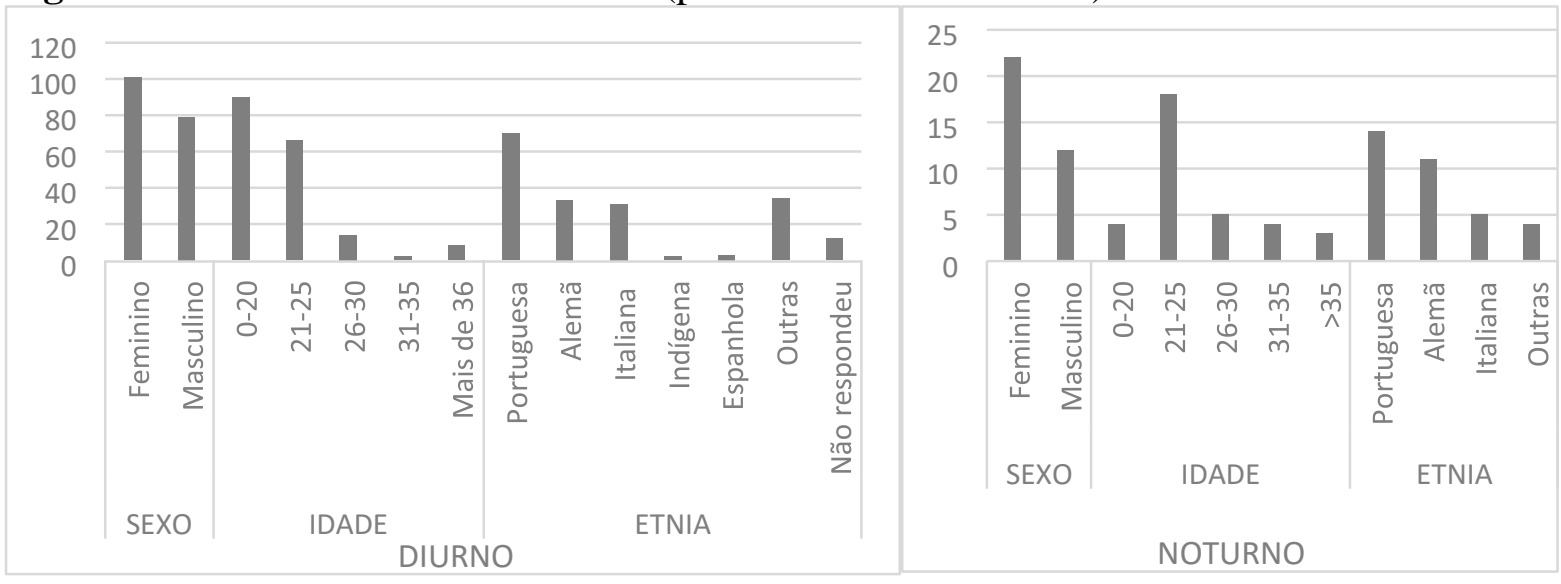

Fonte: Elaboração própria.

O perfil dos estudantes de contabilidade do período noturno se apresenta de forma semelhante ao perfil dos estudantes do período diurno. Pode-se observar que a maioria dos respondentes são do sexo feminino, com idade entre os 21 e 25 anos e etnia portuguesa.

Com relação ao perfil socioprofissional dos estudantes contábeis do período diurno, compreende-se que aqueles que praticam alguma religião totalizam 57,78\%. Em relação ao Revista Eletrônica do Alto Vale do Itajaí - REAVI, v.08, nº 13, p. 013-029, dez 2019 ISSN: 23164190, DOI 10.5965/2316419008112019013 


\section{REAVI}

exercício profissional, apenas $36,11 \%$ trabalham ou realizam estágio na área contábil. Esse dado é esperado uma vez que os alunos iniciantes são a maioria em número, e geralmente começam a realizar atividades remuneradas relacionadas ao seu curso de graduação em fases mais avançadas. Ambos resultados são inferiores aos apresentados na pesquisa de Feil, Diehl e Schuck (2017). A disciplina de Ética e Filosofia Política já foi ou está sendo cursada por $62,78 \%$ dos estudantes e é disponibilizada na quarta fase da grade curricular. Não exige nenhum pré-requisito. Essas constatações podem ser observadas na Figura 2.

Figura 2 - Perfil socioprofissional dos estudantes (período diurno e noturno).

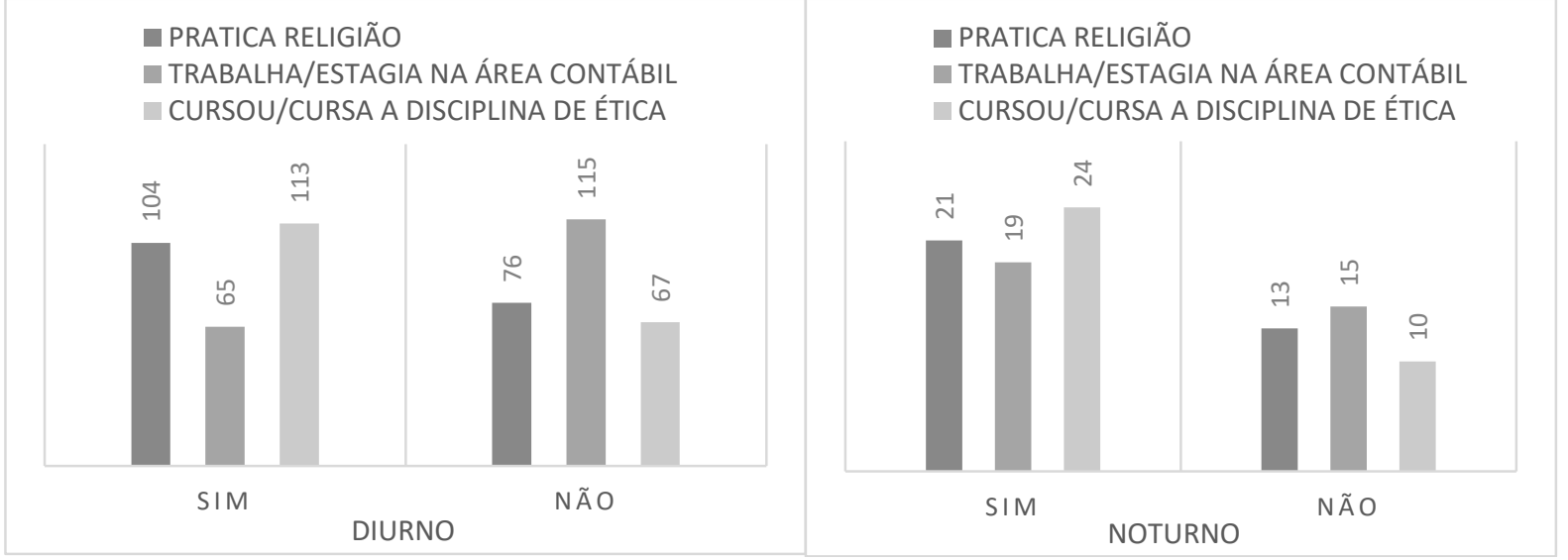

Fonte: Elaboração própria.

Tratando-se dos estudantes noturnos, verifica-se que os mesmos $(55,88 \%)$ tendem a trabalhar mais que os estudantes diurnos $(36,11 \%)$, como pode ser observado na Figura 2. Em relação à religiosidade, ambos períodos apresentaram resultados análogos, indicando que 57,78\% dos estudantes são praticantes de uma religião no período diurno e $61,76 \%$ no período noturno. Quanto a cursar ou já ter cursado a disciplina de Ética e Filosofia Política, observa-se que 70,59\% dos alunos já tiveram contato com a disciplina no período noturno, índice superior ao apontado no período diurno.

Na Figura 3 são apresentadas as respostas obtidas com o questionário com relação à conduta ética dos estudantes contábeis diurnos, que procuraram analisar as questões expondo sua opinião e o grau de conhecimento sobre certas normas contábeis.

A partir dessas indagações, verificou-se que, dos entrevistados (diurnos), 67,22\% concordaram que a disciplina Ética e Filosofia Política contribui na formação do profissional contábil. Desses, 32,78\% concordaram totalmente e 34,44\% concordaram parcialmente (Questão 1 da Figura 3), achado inferior aos 82,2\% do estudo de Feil, Diehl e Schuck (2017).

No que se refere à Questão 2, onde procurou-se analisar a opinião dos estudantes quanto à importância do Código de Ética do Profissional Contábil na conduta ética, 95,53\% concordaram com tal afirmação, totalmente ou parcialmente. A Questão 3 evidencia que 68,72\% dos estudantes concordaram (totalmente ou parcialmente) e 26,56\% não concordaram nem discordaram quanto à clareza e ao conteúdo informacional do CEPC. Os resultados obtidos por Feil, Diehl e Schuck (2017), revelaram que $97,8 \%$ e $87,9 \%$ dos estudantes concordaram com essas mesmas questões, respectivamente.

Revista Eletrônica do Alto Vale do Itajaí - REAVI, v.08, n 13, p. 013-029, dez 2019 ISSN: 23164190, DOI 10.5965/2316419008112019013 


\section{REAVI}

Figura 3 - Respostas dos estudantes do período diurno (em número de estudantes).

- Concordo totalmente $\square$ Concordo parcialmente $\square$ Indiferente $\square$ Discordo parcialmente Discordo totalmente

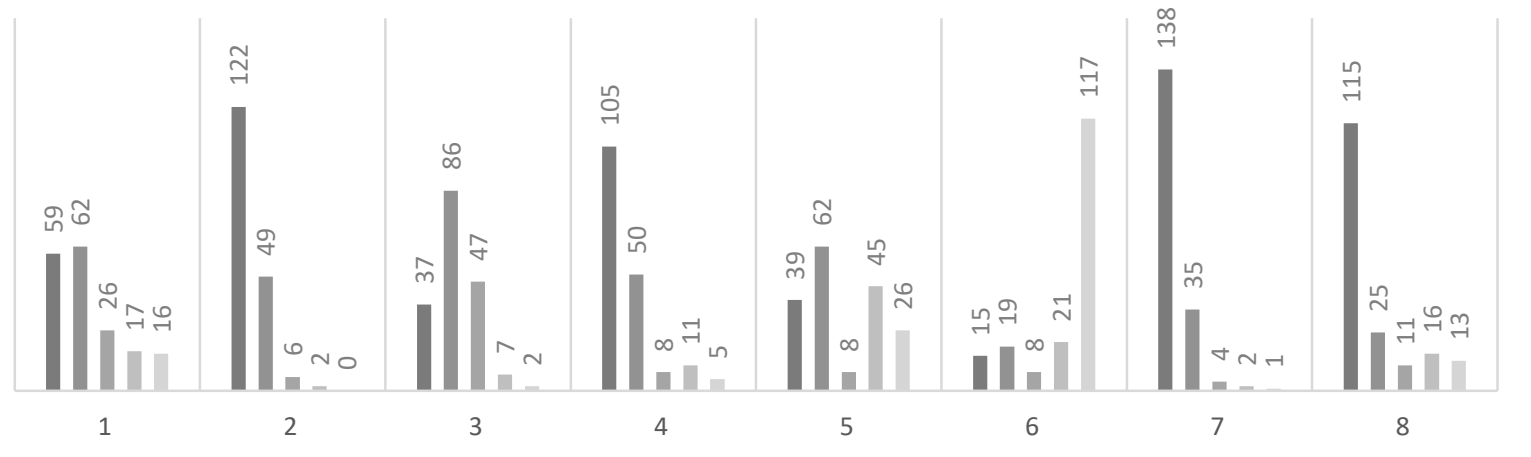

Fonte: Elaboração própria.

Aproximadamente $86 \%$ dos respondentes concordaram, de forma total ou parcial, que é obrigação do contador guardar sigilo de todas as informações relacionadas às atividades operacionais de uma empresa. A análise de Feil, Diehl e Schuck (2017), encontrou 96,9\% de concordância.

Houve maior dispersão nos resultados da Questão 5, onde 56,11\% dos estudantes concordou em apenas alertar um colega de profissão, caso o mesmo esteja tendo condutas antiéticas, enquanto o indicado seria a denúncia. Porém, deve-se levar em conta que a fidelidade ao amigo seja o maior motivo para somente alertá-lo e não propriamente falta de ética. Muitas vezes, o indivíduo pode ter receio de perder o contato ou a amizade com o infrator. Dos respondentes, $14,44 \%$ discordaram totalmente, $4,44 \%$ discordaram parcialmente e $34,44 \%$ assinalaram a alternativa indiferente (não concordam e nem discordam).

A Questão 6 objetivou analisar o conhecimento dos estudantes sobre o seguinte caso: o empregador poderia solicitar ao contador que cometesse atos contrários à legislação, e se não realizasse, deveria demiti-lo. Como resultado, $65 \%$ e $11,67 \%$ discordam totalmente e parcialmente, respectivamente. Porém $18,89 \%$ concordaram com a questão, seja totalmente ou parcialmente. O estudo de Feil, Diehl e Schuck (2017), evidenciou que 82,6\% dos estudantes discordaram dessa afirmação.

Apurou-se, com a Questão 7, que 96,11\% dos respondentes anuíram que o profissional contábil que atentar violações, visando regalias próprias ou para terceiros, deve ser punido pelo CRC/SC e pelo CFC, similarmente ao exposto por Feil, Diehl e Schuck (2017), de 96,9\%.

Por último, a Questão 8 analisou a opinião dos estudantes sobre o seguinte caso: "Imagine que você seja o contador e dono de um escritório de contabilidade. Suponha que um de seus clientes tenha apresentado um lucro de $\mathrm{R} \$ 200.000,00$ ao final do ano de 2016 , e que ele peça sua ajuda para sonegar o imposto de renda declarando um lucro de $\mathrm{R} \$ 100.000,00$. A justificativa alegada pelo cliente para fazer o pedido é a de que o dinheiro que não for pago em imposto será usado para movimentar a economia e gerar mais empregos. Ele acredita que há muita corrupção no governo e que a arrecadação do imposto de renda não será bem investido. Nesse contexto, sua atitude como contador seria não sonegar imposto, apesar da justificativa do cliente". Das respostas, $63,89 \%$ concordaram totalmente com a afirmação, $13,89 \%$ concordaram parcialmente, $6,11 \%$ não

Revista Eletrônica do Alto Vale do Itajaí - REAVI, v.08, n 13, p. 013-029, dez 2019 ISSN: 23164190, DOI 10.5965/2316419008112019013 


\section{REAVI}

concordaram nem discordaram, 8,89\% concordaram parcialmente e 7,22\% discordaram totalmente dessa atitude.

Com base nas respostas dos participantes da pesquisa, constata-se que a maioria dos estudantes de Ciências Contábeis da UFSC do período matutino possuem conhecimento sobre as condutas éticas que devem ser seguidas pelo profissional contábil, para que haja conforme a lei. Contudo, assim como no estudo de Feil, Diehl e Schuck (2017), "algumas respostas sinalizam fragilidades": 56,11\% dos estudantes concordaram em apenas alertar o colega de profissão que cometesse ato ilícito, 23,33\% concordaram ou não tiveram opinião sobre a Questão 7, que permitia ao empregador solicitar ao contador que cometesse atos contrários à lei e demiti-lo caso não realizasse o ato, e somente $77,78 \%$ dos estudantes concordaram que o certo a se fazer é não sonegar imposto, independentemente da justificativa do cliente.

Além disso, deve-se dar apreço à falta de conhecimento técnico sobre tais aspectos por parte de alguns respondentes e não basicamente a falta de ética (FEIL; DIEHL; SCHUCK, 2017). Ressalta-se que 37,22\% dos respondentes ainda não cursou a disciplina de Ética e Filosofia Política e 63,89\% nunca trabalhou nem estagiou na área contábil. Por estas razões, há a possibilidade dos estudantes possuírem pouco conhecimento sobre o referido tema. Segundo Feil, Diehl e Schuck (2017), cursar a disciplina de Ética pode propiciar o entendimento sobre os aspectos legais e profissionais do contador e sobre os deveres dos órgãos reguladores do exercício profissional.

$\mathrm{Na}$ Figura 4 estão representadas as respostas dos estudantes noturnos quanto ao conhecimento sobre a ética profissional. No geral, não se observou grande divergência entre as observações, levando-se em conta os dois períodos. Os itens que expuseram maior discordância entre os resultados foram a Questão 4, 6 e 8. Na Questão 4, que se refere ao sigilo das informações contábeis, aproximadamente 59\% dos estudantes diurnos concordaram totalmente com a afirmação contra $41 \%$ dos estudantes noturnos. Quanto à Questão 6, que trata da possibilidade do empregador demitir um contador caso esse não aceite agir contra a legislação, 8,33\% e 17,65\% concordaram plenamente com a sentença, em relação aos mesmos períodos, respectivamente. Por fim, na última questão, $64 \%$ dos alunos do período diurno e $79 \%$ dos alunos do período noturno concordaram totalmente que o correto a ser feito, independentemente da justificativa do cliente, é não sonegar imposto.

Figura 4 - Respostas dos estudantes do período noturno (em número de estudantes).

- Concordo totalmente $\square$ Concordo parcialmente $\square$ Indiferente $\square$ Discordo parcialmente $\square$ Discordo totalmente

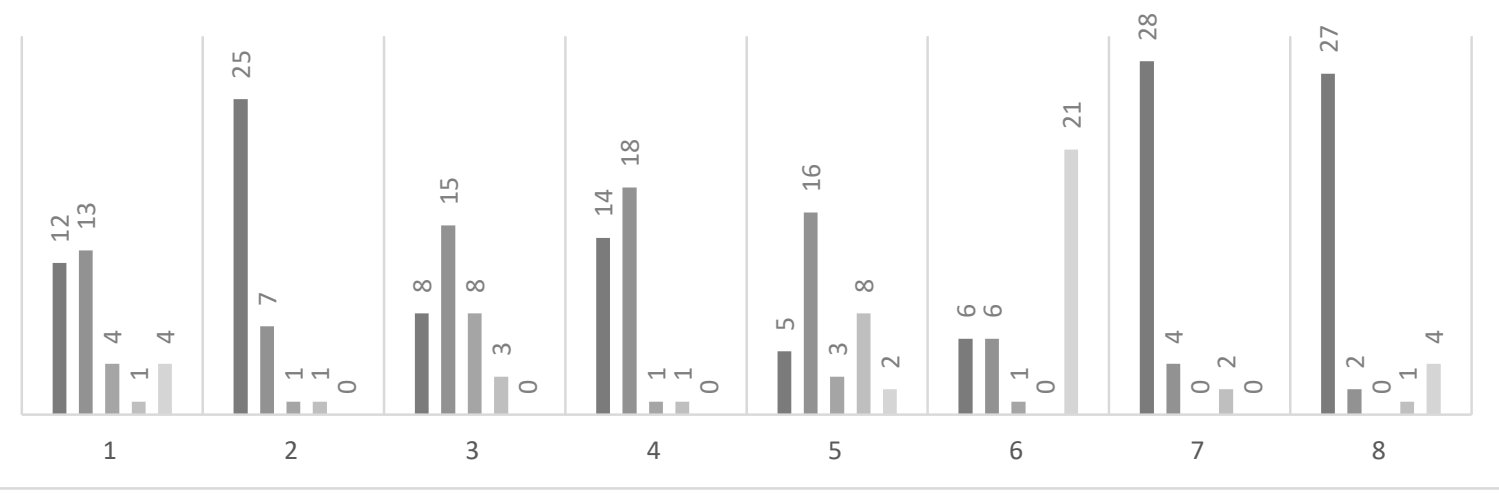

Fonte: Elaboração própria.

Revista Eletrônica do Alto Vale do Itajaí - REAVI, v.08, n 13, p. 013-029, dez 2019 ISSN: 23164190, DOI 10.5965/2316419008112019013 


\section{REAVI}

\subsection{Correlação de Spearman}

As correlações analisadas se restringem às variáveis do perfil socioprofissional em relação ao conhecimento dos estudantes de Ciências Contábeis sobre ética profissional. O relacionamento com maior $p$-value (período diurno) revela baixo grau de correlação $(0,232)$, como pode ser observado na Tabela 2.

Tabela 2 - Matriz de correlação - estudantes do período diurno.

\begin{tabular}{lrrrrrrrrrrrrrr}
\hline & \multicolumn{1}{c}{ V1 } & V2 & V3 & V4 & V5 & V6 & Q 1 & Q 2 & Q 3 & Q4 & Q 5 & Q 6 & Q 7 & Q 8 \\
\hline V1 & 1,00 & & & & & & & & & & & & & \\
V2 & 0,03 & 1,00 & & & & & & & & & & & & \\
V3 & 0,01 & $-0,13$ & 1,00 & & & & & & & & & & & \\
V4 & 0,20 & $-0,09$ & 0,10 & 1,00 & & & & & & & & & & \\
V5 & $-0,09$ & $-0,03$ & $-0,04$ & 0,06 & 1,00 & & & & & & & & & \\
V6 & 0,10 & $-0,27$ & $-0,05$ & 0,05 & 0,23 & 1,00 & & & & & & & & \\
Q 1 & $-0,04$ & 0,05 & 0,06 & 0,01 & $-0,15$ & $-0,21$ & 1,00 & & & & & & & \\
Q 2 & $-0,02$ & $-0,04$ & 0,13 & $-0,09$ & $-0,01$ & $-0,05$ & 0,40 & 1,00 & & & & & & \\
Q 3 & 0,15 & $-0,23$ & 0,16 & 0,23 & 0,14 & 0,15 & 0,02 & 0,17 & 1,00 & & & & & \\
Q 4 & 0,12 & $-0,08$ & $-0,09$ & 0,08 & 0,09 & 0,13 & $-0,07$ & 0,02 & 0,15 & 1,00 & & & & \\
Q 5 & $-0,14$ & 0,05 & $-0,03$ & $-0,10$ & 0,07 & $-0,10$ & 0,07 & $-0,04$ & $-0,13$ & 0,02 & 1,00 & & & \\
Q 6 & $-0,02$ & 0,15 & 0,03 & 0,02 & $-0,03$ & $-0,22$ & $-0,11$ & $-0,12$ & $-0,17$ & $-0,02$ & 0,19 & 1,00 & & \\
Q 7 & 0,09 & $-0,08$ & $-0,03$ & 0,03 & $-0,03$ & 0,14 & 0,01 & 0,24 & 0,33 & 0,14 & $-0,13$ & $-0,11$ & 1,00 & \\
Q 8 & 0,10 & $-0,12$ & $-0,05$ & 0,02 & $-0,04$ & 0,06 & 0,00 & $-0,01$ & $-0,04$ & 0,03 & $-0,10$ & $-0,01$ & 0,05 & 1,00 \\
\hline
\end{tabular}

Fonte: Elaboração própria.

Os resultados revelam que o fato dos estudantes terem cursado ou estarem cursando a disciplina Ética e Filosofia Política pode explicar por que eles: a) concordam que o CEPC apresenta informações claras e suficientes quando à conduta de ética do profissional contábil $(0,147)$; b) concordam que o contador tem a obrigação de guardar sigilo de todas as informações da empresa $(0,128)$; c) discordam que o empregador poderia solicitar que o seu empregado cometesse atos ilícitos $(-0,220)$; d) concordam que os profissionais que cometem infrações visando vantagens próprias ou para terceiros, devem sofrer punições pelo CRC/SC-CFC $(0,137)$.

A prática de um tipo de religião pode explicar porque os estudantes concordam que o CEPC apresenta informações claras e suficientes sobre a ética da profissão $(0,232)$. Já, a idade pode ser um fator que esclarece a concordância dos estudantes quanto à clareza do $\operatorname{CEPC}(-0,226)$ e a discordância dos mesmos quanto à Questão $6(0,145)$. A etnia e o trabalho na área contábil podem esclarecer também a Questão 3, com $p$-value igual a 0,159 e 0,135, respectivamente. Vale destacar que não houve nenhuma correlação mediana ou forte referente ao período diurno. Desta forma, pode-se afirmar que as variáveis possuem baixa correlação, entretanto significativa influência nas atitudes éticas dos estudantes de contabilidade.

Com referência à Tabela 3, observa-se que as correlações entre as variáveis e o conhecimento ético dos participantes é maior na análise do período noturno. Porém, a amostra dos estudantes do período noturno contempla apenas 34 estudantes de contabilidade, enquanto a amostra do período diurno abrange 180 estudantes.

Revista Eletrônica do Alto Vale do Itajaí - REAVI, v.08, n 13, p. 013-029, dez 2019 ISSN: 23164190, DOI 10.5965/2316419008112019013 


\section{REAVI}

Tabela 3 - Matriz de correlação - estudantes do período noturno.

\begin{tabular}{|c|c|c|c|c|c|c|c|c|c|c|c|c|c|c|}
\hline & V1 & $\mathbf{V 2}$ & V3 & V4 & V5 & V6 & Q 1 & Q 2 & Q 3 & Q 4 & Q 5 & Q 6 & Q 7 & Q 8 \\
\hline V1 & 1,00 & & & & & & & & & & & & & \\
\hline $\mathbf{V} 2$ & 0,09 & 1,00 & & & & & & & & & & & & \\
\hline V3 & $-0,16$ & $-0,04$ & 1,00 & & & & & & & & & & & \\
\hline V4 & 0,05 & 0,22 & $-0,34$ & 1,00 & & & & & & & & & & \\
\hline V5 & 0,09 & 0,16 & 0,03 & $-0,09$ & 1,00 & & & & & & & & & \\
\hline V6 & $-0,07$ & 0,04 & $-0,17$ & 0,16 & 0,34 & 1,00 & & & & & & & & \\
\hline Q 1 & 0,28 & 0,02 & $-0,34$ & 0,22 & $-0,26$ & $-0,29$ & 1,00 & & & & & & & \\
\hline Q 2 & 0,16 & 0,14 & $-0,28$ & 0,48 & $-0,03$ & 0,14 & 0,47 & 1,00 & & & & & & \\
\hline Q 3 & $-0,01$ & $-0,30$ & 0,01 & 0,32 & 0,09 & 0,23 & 0,08 & 0,19 & 1,00 & & & & & \\
\hline Q 4 & $-0,19$ & $-0,40$ & 0,07 & 0,02 & $-0,10$ & 0,21 & 0,14 & 0,25 & 0,44 & 1,00 & & & & \\
\hline Q 5 & $-0,09$ & $-0,22$ & $-0,22$ & 0,16 & 0,10 & $-0,04$ & $-0,10$ & 0,01 & 0,18 & $-0,07$ & 1,00 & & & \\
\hline Q 6 & 0,06 & 0,04 & $-0,02$ & $-0,04$ & 0,19 & $-0,08$ & $-0,15$ & $-0,19$ & $-0,02$ & $-0,34$ & $-0,04$ & 1,00 & & \\
\hline Q 7 & 0,04 & 0,02 & $-0,14$ & 0,10 & $-0,03$ & $-0,25$ & 0,10 & 0,14 & 0,28 & 0,13 & 0,22 & 0,14 & 1,00 & \\
\hline Q 8 & 0,44 & 0,10 & $-0,09$ & $-0,05$ & 0,12 & $-0,30$ & 0,02 & 0,11 & 0,06 & $-0,17$ & $-0,15$ & 0,20 & 0,40 & 1,00 \\
\hline
\end{tabular}

Fonte: Elaboração própria.

Verifica-se que há relacionamento com grau moderado de correlação, como o $p$-value de 0,4369. Os estudos indicam que o gênero dos respondentes pode explicar por que eles concordam com não sonegar imposto, independente da justificativa do cliente (Questão 8).

A Questão 1 pode ser explicada pelo gênero, pela etnia, pela religiosidade, pela experiência profissional e por estar cursando ou já ter cursado a disciplina de Ética com p-value de 0,28478, $0,3382,0,2240,-0,26314$ e $-0,2928$, respectivamente. As Questões 2 e 3, que tratam da importância e da clareza do CEPC também podem ser explicadas pela religiosidade ( $p$-value $=0,4810$ e 0,3200). A idade dos participantes explica por que os mesmos concordam que os contadores têm a obrigação de guardar sigilo das informações da empresa $(-0,3974)$ e discordam de apenas alertar um amigo de profissão, caso cometa atos contrários à legislação $(-0,2230)$.

\subsection{Teste Kruskal-Wallis}

Para esta pesquisa, aplicou-se o teste de Kruskal-Wallis, dado que é um teste não paramétrico utilizado para comparar populações. Optou-se por aplicá-lo somente com os dados dos estudantes diurnos, considerando a diferença no número da amostra, com o objetivo de apresentar um resultado com maior grau de confiabilidade. Os resultados são ilustrados na Tabela 4.

Tabela 4 - Teste Kruskal-Wallis.

\begin{tabular}{lrrrrrrrr}
\hline & Q 1 & Q 2 & Q 3 & Q 4 & Q 5 & Q 6 & Q 7 & Q 8 \\
\hline A atitude ética em relação ao gênero & 0,789 & 0,986 & 0,017 & 0,995 & 0,240 & 0,527 & 0,407 & 0,147 \\
A atitude ética em relação à idade & 0,131 & 0,921 & 0,078 & 0,699 & 0,878 & 0,419 & 0,451 & 0,632 \\
A atitude ética em relação à etnia & 0,444 & 0,532 & 0,017 & 0,591 & 0,673 & 0,906 & 0,953 & 0,384 \\
A atitude ética em relação à religião & 0,261 & 0,315 & 0,023 & 0,847 & 0,166 & 0,497 & 0,976 & 0,664 \\
Atitude ética x experiência profissional & 0,204 & 0,765 & 0,112 & 0,089 & 0,907 & 1,000 & 0,713 & 0,468 \\
Atitude ética x Cursar ou não Ética & 0,018 & 0,309 & 0,071 & 0,381 & 0,095 & 0,013 & 0,103 & 0,312 \\
\hline
\end{tabular}

Fonte: Elaboração própria.

Revista Eletrônica do Alto Vale do Itajaí - REAVI, v.08, n 13, p. 013-029, dez 2019 ISSN: 23164190, DOI 10.5965/2316419008112019013 


\section{REAVI}

Revelou-se, com a aplicação do teste, que algumas questões apresentaram um p-value < 0,05. Com um grau de confiança de $95 \%$, esses resultados indicam que a hipótese nula foi rejeitada, ou seja, há diferença significativa entre os grupos analisados referentes a essas questões.

A hipótese sobre o gênero indicou que a Questão 3 possui um $p$-value $<0,05(0,0171)$. Rejeita-se a hipótese nula, indicando diferenças relevantes entre os estudantes do sexo masculino e feminino, tratando-se dessa questão. A literatura apresenta que é possível que as mulheres, com o objetivo de preservarem sua reputação, posicionem-se de forma mais coerente em relação aos padrões éticos. Apesar das mulheres estarem ocupando espaços na sociedade que comumente eram reservados somente aos homens, ainda ocorrem diferenças no que se refere às oportunidades e aos rendimentos entre os gêneros, mesmo exercendo funções congêneres (CAMBOTA; PONTES, 2007).

Portanto, essa diferença significativa deve-se ao fato do sexo feminino, possivelmente, possuir uma conduta mais ética. Deve-se levar em conta, porém, que essa mesma diferença só foi encontrada na Questão 3, concluindo que em todas as outras questões não foram apresentadas divergências consistentes na comparação de gênero.

Em relação à idade dos estudantes não foi apresentado um $p$-value inferior a $5 \%$. Dessa forma, aceita-se a hipótese nula e infere-se que não há diferença significativa entre os estudantes com idades diferentes. Esse resultado é contrário ao apresentado pelo estudo de Feil, Diehl, Schuck (2017), no qual encontrou-se diferenças relevantes nesse aspecto. Pode-se concluir que os jovens possuem uma maturidade avançada sobre a questão da ética desde o início da vida acadêmica, que se tornam mais conscientes pela grande repercussão da mídia sobre os problemas éticos na sociedade.

Com base na etnia dos estudantes, revela-se que as respostas da Questão 3 apresentaram diferenças significativas, com $p$-value $=0,0225$. Desde modo, rejeita-se a hipótese nula. Segundo Ho (2010), as diferenças na percepção ética de cada grupo étnico podem ocorrer devido às diferentes culturas, compreendendo que uma etnia pode considerar algo ético e, outra, não. Além disso, as atitudes éticas podem estar vinculadas ao nível de corrupção de determinado país, pois os indivíduos podem comparar as normas locais como guia de conduta ética e segui-las para tomada de decisão.

Em relação à religiosidade dos estudantes, conclui-se que há diferença significativa em relação aos alunos que praticam algum tipo de religião ou não praticam, uma vez que foi encontrado um p-value inferior à $5 \%$ em relação à Questão 3, rejeitando a hipótese nula. Da amostra do estudo, aproximadamente $58 \%$ e $42 \%$ dos estudantes afirmaram praticar e não praticar nenhuma religião, respectivamente. Já, no estudo de Feil, Diehl, Schuck (2017), 73\% da amostra eram praticantes de algum tipo de religião, enquanto $27 \%$ dos estudantes não praticavam. Apesar dessa diferença entre as amostras dos estudos, o resultado do teste Kruskal Wallis apresentou a mesma diferença entre as médias. Conforme Alves, Lisboa, Weffort et al. (2007), o profissional que se reconheça praticante de uma religião inclina-se a atender ao código de ética por ele conter os mesmos princípios que guiam sua vida religiosa e indicam desaprovação de ações antiéticas.

Como observado na Tabela 4, a hipótese referente à experiência profissional indica que não há diferença significativa das médias, não apresentando nenhuma questão com $p$-value inferior a 5\%. Neste sentido, aceita-se a hipótese nula. Este resultado não é condizente com o apontado por Feil, Diehl e Schuck (2017), cujo estudo revelou $p$-value < 0,05. Pode-se concluir com este resultado que trabalhar ou fazer estágio na área contábil não acarreta diretamente em maior conhecimento ético. A maior parte dos estudantes diurnos ainda não trabalha na área contábil (65\%), portanto, a análise pode ter sido prejudicada devido a este fator.

Revista Eletrônica do Alto Vale do Itajaí - REAVI, v.08, n 13, p. 013-029, dez 2019 ISSN: 23164190, DOI 10.5965/2316419008112019013 
Na Questão 1, encontra-se $p$-value $=0,0182$ em relação aos estudantes que já cursaram ou estão cursando a disciplina de Ética e Filosofia Política e os que ainda não cursaram a mesma. A hipótese apresenta diferenças significativas quanto às respostas dos alunos. A possibilidade dessa diferença indica que os estudantes que já cursaram a disciplina de Ética e Filosofia Política possuem maior atitude ética é consideravelmente maior que a proposição contrária, visto que a ementa da disciplina abrange o Código de Ética do Profissional Contábil e tem o intuito principal de conscientizar os alunos sobre as responsabilidades éticas da profissão. A média dos resultados apresentou um percentual em torno de $67 \%$, ou seja, um nível superior aos $60 \%$ dos estudantes que cursaram ou cursam a disciplina Ética e Filosofia Política. Esta observação significa que a educação ética apresentou impacto essencial na conduta e percepção da ética dos futuros profissionais.

\section{Considerações finais}

Os profissionais contábeis são de grande importância à sociedade e possuem muitas responsabilidades no exercício de sua profissão. É seu dever agir de maneira ética, tendo como guia o Código de Ética do Profissional Contábil. A imagem do contador diante da sociedade não é nada mais que o reflexo de suas atitudes. Portanto, agir de forma antiética afeta diretamente a reputação do indivíduo. O objetivo da referente pesquisa foi o de analisar a compreensão e a percepção dos estudantes à cerca da ética profissional e qual a relação entre as variáveis analisadas e o conhecimento demonstrado.

Os resultados obtidos com a análise do perfil socioprofissional dos estudantes de contabilidade concluem que a maioria deles são do sexo feminino, com idade até 25 anos e praticantes de alguma religião; as etnias predominantes são a portuguesa e a alemã. Em relação aos estudantes do período diurno, a maioria não trabalha na área contábil no momento, ao contrário dos alunos do período noturno, no qual a maioria já tem experiência profissional. A disciplina Ética e Filosofia Política já foi ou está sendo cursada pela maior parte da amostra. Referente às questões éticas, os estudantes em geral concordam que a disciplina apontada contribui para a formação do profissional contábil e que o CEPC, além de ser importante na conduta ética, possui informações suficientes e objetivas quanto à essa conduta profissional. Em média, 86\% dos estudantes aprovam o sigilo das informações e apenas 39\% discordam de apenas alertar um colega de profissão, quanto este comete atos ilícitos. Além disso, a maior parte dos estudantes concordam com a punição dos infratores do Código de Ética e em não sonegar imposto e discordam em relação ao empregador demitir um contador caso este não realize atos contrários à lei quando solicitado.

Os estudantes em média apresentaram conhecimento ético sobre as questões analisadas. Verifica-se, porém, um reflexo mais frágil na Questão 3 em relação às demais, onde $56,11 \%$ dos estudantes concordou em apenas alertar um colega de profissão, caso o mesmo esteja tendo condutas antiéticas, enquanto o mais indicado seria a denúncia. Porém, considera-se a fidelidade ao amigo como o maior motivo para esta resposta, e não diretamente e somente falta de ética por parte dos respondentes. Ademais, o desconhecimento sobre a denúncia pode ser relevante, visto que esta obrigação não existe para todas as outras profissões.

$\mathrm{Na}$ aplicação do teste de Spearman, o relacionamento com maior $p$-value (período diurno) revelou baixo grau de correlação $(0,232)$. Esta análise indica que a variável religião explica porque os estudantes concordam que o CEPC apresenta informações claras e suficientes sobre a ética da profissão. Revelou-se também que o fato dos estudantes terem cursado ou estarem cursando a disciplina Ética e Filosofia Política, a prática de um tipo de religião, a etnia e a experiência Revista Eletrônica do Alto Vale do Itajaí - REAVI, v.08, n 13, p. 013-029, dez 2019 ISSN: 23164190, DOI 10.5965/2316419008112019013 


\section{REAVI}

profissional possuem significativa influência nas atitudes éticas dos estudantes de contabilidade. O teste Kruskal-Wallis apontou que as hipóteses testadas quanto ao gênero, a religiosidade, a etnia e a cursar ou estar cursando a disciplina de Ética possuem diferenças significativas entre as médias.

Vale destacar que os resultados desta pesquisa se aplicam apenas à Universidade Federal de Santa Catarina, pois certos achados foram diferentes dos apresentados pela literatura referência da pesquisa. Desta forma, estudantes de outras localidades e instituições podem apresentar resultados diferentes, como não serem influenciados pelas variáveis que foram significativas neste estudo ou serem influenciados em maior grau por outros fatores observados.

Salienta-se a importância de a academia estar atenta à ementa curricular, contemplando disciplinas dessa natureza, além de preparar seu corpo docente para a abordagem e o debate dessa temática em sala de aula, durante o processo de formação do profissional (FEIL; DIEHL; SCHUCK, 2017). Assim, há a possibilidade de conscientizar mais estudantes à cerca das responsabilidades, das condutas éticas que devem ser seguidas pelos profissionais e do comprometimento que deve existir no exercício de suas funções.

Conclui-se, com base neste estudo, que os estudantes tendem a agir de forma ética e que as variáveis individuais (idade, religião, etnia, experiência profissional, já ter cursado a disciplina de Ética) são fatores determinantes para essa conduta. Este resultado está em conformidade com o apresentado por Feil, Diehl e Schuck (2017), por Weiler (2017) e por Feil (2016).

\section{REFERÊNCIAS}

ALVES, A, F. J. D. S.; LISBOA, N. P.; WEFFORT, E. F. J.; ANTUNES, M. T. P. Um estudo empírico sobre a importância do código de ética profissional para o contabilista. Revista Contabilidade \& Finanças - USP, v. 18, n.spe, p. 58-68, 2007.

ANJOS, L. C. M.; RANCIARO NETO; A.; SILVA, D. J. C.; MIRANDA, L. C. Código de ética e o comportamento ético na vida pessoal: um estudo junto as pessoas envolvidas com a contabilidade. Revista de Contabilidade da UFBA, Salvador, v. 5, n. 2, p. 4-19, 2011.

ANZEH, B. A.; ABED, S. The extent of accounting ethics education for bachelor students in Jordanian universities. Journal of Management Research, v. 7, n. 2, p. 121-143, 2015.

ARRUDA, M. C. C. Fundamentos de Ética Empresarial e Econômica. $2^{\text {a }}$. ed. São Paulo: Atlas, 2003.

BAYOU, M. E.; REINSTEIN, A.; WILLIAMS, P. F. To tell the truth: A discussion of issues concerning truth and ethics in accounting. Accounting, Organizations and Society, v. 36, n. 2, p. 109-124, 2011.

CARDOSO, Jorge Luiz; SOUZA, Marcos Antônio de; ALMEIDA, Lauro Brito. Perfil do Contador na atualidade: um estudo exploratório. Revista BASE de Administração e Contabilidade da Unisinos, v. 3, n. 3, p. 275-284, 2006.

CONSELHO FEDERAL DE CONTABILIDADE - CFC. Resolução CFC N 803, de 10 de outubro de 1996: aprova o Código de Ética Profissional do Contador - CEPC. Brasília, 1996. Disponível em: <www.cfc.org.br/sisweb/sre/docs/RES_803.doc> Acesso em 08/09/2017.

Revista Eletrônica do Alto Vale do Itajaí - REAVI, v.08, n 13, p. 013-029, dez 2019 ISSN: 23164190, DOI 10.5965/2316419008112019013 


\section{REAVI}

CRISTINA, N.; FLORINA, P. M. Ethics in accounting. Annals of the University of Oradea, Economic Science Series, v. 17, n. 3, p. 1352, 2008.

DELLA, Flora V. A.; CEOLIN, R.; NEUBAUER, V. S.; LEAL, R. B.; SILVA, E. M. T.; VIRGOLIN, I. W. C.; CAMARGO, B. F. Ética no horizonte do profissional contábil. Revista Interdisciplinar de Ensino, Pesquisa e Extensão, v. 2, n. 1, p. 1-13, 2014.

FEIL, Alexandre André. Análise das variáveis intervenientes na tomada de decisão ética do profissional contábil. Enfoque: Reflexão Contábil, v. 35, p. 75-93, 2016.

FEIL, Alexandre A.; DIEHL, Liciane; SCHUCK, Rogério José. Ética profissional e estudantes de contabilidade: análise das variáveis intervenientes. Cad. EBAPE.BR, v. 15, 2017.

HO, J. A. Ethical perception: are differences between ethnic groups situation dependent?

Business Ethics: An European Review, v. 19, n. 2, p. 154-182, 2010.

IUDÍCIBUS, S.; MARTINS, E.; GELBECK, E. R.; SANTOS, A. Manual de Contabilidade Societária: Aplicável a todas as Sociedades de Acordo com as Normas Internacionais e do CPC. $1^{a}$ edição FIPECAFI. São Paulo: Atlas. 2010.

JACKLING, B.; COOPER; B. J.; LEUNG, P.; DELLAPORTAS, S. Professional accounting bodies perceptions of ethical issues, causes of ethical failure and ethics education. Managerial Auditing Journal, v. 22, n. 9, p. 928-944, 2007.

KISH-GEPHART, J. J.; HARRISON, D. A.; TREVIÑO, L. K. Bad apples, bad cases, and bad barrels: Meta-analytic evidence about sources of unethical decisions at work. Journal of Applied Psychology, v. 95, p. 1-31, 2010.

LISBOA, L. P. Ética geral e profissional em contabilidade. 2. ed. São Paulo: Atlas, 2010.

LOPES, J. E. G.; RIBEIRO FILHO, J. F.; VASCONCELOS, M. T. C.; PEDERNEIRAS, M. M. M. Uma análise avaliativa de atitudes de estudantes de ciências contábeis e dilemas éticos sob uma perspectiva de gênero, maturidade acadêmica e ambiente institucional. Ensaio: Avaliação e Políticas Públicas em Educação, v. 14, n. 51, p. 209-222, 2006.

MARION, J. C. Contabilidade Empresarial. 16 ed. São Paulo: Atlas, 2012.

MORAES, M. C. C.; SILVA, A. M. C.; CARVALHO, F. A. A. O comportamento dos futuros contabilistas perante diferentes dilemas éticos. Pensar Contábil, v. 12, n. 48, p. 22-30, 2010.

MOTTA, N. S. Ética e vida profissional. Rio de janeiro: Âmbito Cultural, 1984.

ONYEBUCHI, V. N. Ethics in accounting. International Journal of Business and Social Science, v. 2, 2011.

Revista Eletrônica do Alto Vale do Itajaí - REAVI, v.08, n 13, p. 013-029, dez 2019 ISSN: 23164190, DOI 10.5965/2316419008112019013 
OTALOR, J. I.; EIYA, O. Ethics in accounting and the reliability of financial information. European Journal of Business and Management, v. 5, 2013.

PARKER, L. D. Professional accounting body ethics: In search of the private interest. Accounting, Organizations and Society, v.19, n. 6, p. 507-525, 1994.

SANTOS, L. M.; JESUS, M. L. A Importância da Ética na Formação do Profissional de Contabilidade. Pensar Contábil, v. 4, n. 14, 2002.

SHINZAKI, K.; CORRÊA, D. V.; FERREIRA, C. R. Uma breve reflexão sobre a importância da ética na profissão contábil. Revista Contemporânea de Contabilidade, v. 2, n. 3, p. 5772 , 2005.

SMITH, L. M. A fresh look at accounting ethics (or Dr. Smith goes to Washington). Accounting Horizons, v. 17, p. 47-49, 2003.

VÁZQUEZ, A. S. Ética. 32ª . ed. Rio de Janeiro: Civilização Brasileira, 2011.

WEILER, Pâmela Francine. Análise das variáveis intervenientes relacionadas à ética dos profissionais contábeis. 2016. Trabalho de Conclusão de Curso. 67 f. (Ciências Contábeis) Univates, Lageado, 2016. 